\title{
Laser Treatment for Glaucoma: Newer Procedures
}

\section{Dieudonne Kaimbo Wa Kaimbo*}

Ophthatmotogy and Biophysics, University of Kinshasa Democratic, Republic of Congo

Trabeculectomy with Mitomycin-C (MMC) and glaucoma drainage device implantation remain the most commonly performed surgical procedures for the treatment of Open Angle Glaucoma (OAG). Numerous studies have shown good efficacy for these surgical procedures [1-3]; however, a high rate of complications [4] has prompted the glaucoma community to search for alternative surgeries to treat $\mathrm{OAG}$.

There is a trend towards using lasers earlier in the course of treatment of open-angle glaucoma [5]. From the patient and physician perspectives, laser therapy is less invasive and more easily performed than most incisional ophthalmic surgeries. When successful, glaucoma laser therapy is also remarkably cost-effective. Lastly, though not to be minimized, complications following glaucoma laser therapy tend to be less serious and more easily treated [6]. A variety of glaucomatous pathologic processes may be addressed employing photocoagulation and photodisruption, the major modalities of laser energy application. Traditional procedures include Argon Laser Trabeculoplasty, Argon iridoplasty, Peripheral Laser Iridotomy, and Cyclophotocoagulation. Newer procedures include selective Yag Laser Trabeculoplasty, endoscopic cyclophotocoagulation, YagTransconjunctival Laser Revision of Late Failing filters and excimer laser trabeculotomy.

Glaucoma specialists continue to look for "blebless" surgical techniques with which to treat patients whose medications have failed them. The increasing use of selective laser trabeculoplasty and endoscopic cyclophotocoagulation reflects this trend. Research into excimer laser trabeculostomy, an abinterno approach to drainage, is also reflective of this movement. As interest increases in blebless procedures, it is highly possible that lasers will play an increasing role in surgical management.

\section{References}

1. AGIS Investigators (2001) The Advanced Glaucoma Intervention Study: 9 Comparison of glaucoma outcomes in black and white patients within treatment groups. Am J Ophthalmol 132: 311-320.

2. Musch DC, Gillespie BW, Niziol LM, Lichter PR, Varma R (2011) Intraaocular pressure control and long-term visual field loss in the Collaborative Initial Glaucoma. Ophthalmology 118: 1766-1773.

3. Gedde SJ, Schiffman JC, Feuer WJ, Herndon LW, Brandt JD, et al. (2009) Three-year follow-up of the tube versus trabeculectomy study. Am J Ophthalmol 148: 670-684.

4. Gedde SJ, Singh K, Schiffman JC, Feuer WJ (2012) The Tube Versus Trabeculectomy Study: interpretation of results and application to clinical practice. Curr Opin Ophthalmol 23: 118-126

5. Meyer JJ, Lawrence SD (2012) What's new in laser treatment for glaucoma? Curr Opin Ophthalmol 23: 111-117.

6. Smith ND, Crabb DP, Garwaj-Heath DF (2011) An exploratory study of visual search performance in glaucoma. Ophthalmic Physiol Opt 311: 225-232.
*Corresponding author: Dieudonne Kaimbo Wa Kaimbo, Ophthatmotogy and Biophysics, University of Kinshasa Democratic, Republic of Congo, E-mail: dieudonne_kaimbo@yahoo.com

Received October 21, 2013; Accepted October 23, 2013; Published October 25, 2013

Citation: Kaimbo DKW (2013) Laser Treatment for Glaucoma: Newer Procedures. J Clin Case Rep 3: e119. doi:10.4172/2165-7920.1000e119

Copyright: ( 2013 Kaimbo DKW. This is an open-access article distributed under the terms of the Creative Commons Attribution License, which permits unrestricted use, distribution, and reproduction in any medium, provided the original author and source are credited. 